\title{
詁NERF SPACQE
}

A QUÍMICA, O IMAGINÁRIO E AS CRIANÇAS: notas sobre o currículo pós-moderno

\author{
CHEMISTRY, IMAGINARY AND CHILDREN: notes on the post-modern \\ curriculum
}

\section{LA QUÍMICA, EL IMAGINARIO Y LOS NIÑOS: notas sobre el currículo pós- moderno}

\author{
Aldo Sena de Oliveira \\ Doutor em Química pela Universidade Federal de Santa Catarina - UFSC. Professor do \\ Departamento de Ciências Exatas e Educação da UFSC/Câmpus Blumenau. \\ aldo.sena@ufsc.br
}

\section{Patrícia Bulegon Brondani}

Doutora em Química Orgânica pela Universidade de São Paulo - USP. Professora do Departamento de Ciências Exatas e Educação da Universidade Federal de Santa Catarina -

UFSC/Câmpus Blumenau.

p.b.brondani@ufsc.br

\section{Lidiane Meier}

Doutora em Química pela Universidade Federal de Santa Catarina - UFSC. Professora do

Departamento de Ciências Exatas e Educação da UFSC/Câmpus Blumenau.

lidiane.meier@ufsc.br

Recebido para avaliação em 01/03/2017; Aceito para publicação em 04/10/2017.

\section{RESUMO}

A elaboração de propostas pedagógicas para o trabalho com crianças deve ocorrer em consonância com o contexto histórico em que elas estejam inseridas. Nesse sentido, as práticas desenvolvidas em décadas anteriores ainda permeiam o currículo da educação infantil e do ensino fundamental, acarretando incompatibilidade entre estes corpos e subjetividades. Em meio às atuais políticas de alterações curriculares, faz-se necessário um olhar mais aprofundando para as questões que envolvem a escola, o currículo e o planejamento educacional, haja vista que a abordagem construtivista, ainda que estabelecida em décadas anteriores, respalda teoricamente a elaboração de propostas metodológicas para a educação. Assim, propõe-se a realização de atividades envolvendo experimentos químicos, buscando-se as representações no plano mental que ampliem a curiosidade, viabilizem explorações do mundo físico e novas abstrações. Defendo o ensino de química para crianças, não com um trabalho excessivo com conteúdo de elevado nível de abstração, mas com temáticas compatíveis com o grau de desenvolvimento psicológico destas crianças. Abordagens experimentais que envolvem a química nas primeiras séries de escolarização, sendo alternativas viáveis e possíveis para ampliar as formas de construção e de conhecimento na infância.

Palavras-chave: Química; Experimentos; Construtivismo; Infância.

\section{ABSTRACT}

The elaboration of pedagogical proposals applied for children must occur in consonance with the historical context in which the children are inserted. In this sense, practices developed during the last decades still permeate the curriculum in elementary and middle education, leading to an 
Dossiê: Diálogos Interdisciplinares em Psicologia da Educação

|A Química, o imaginário e as crianças: notas sobre o currículo pós-moderno|

|Aldo Sena de Oliveira | Patrícia Bulegon Brondani | Lidiane Meier |

incompatibility between these scenario and subjectivities. In the midst of the current curriculum change policies, a deeper look at the issues surrounding school, curriculum, and educational planning is needed. The constructivist approach, although established in previous decades, theoretically supports the elaboration of methodological proposals for education. This work proposes that activities involving chemical experiments are carried out, aiming at the creation of representations in the mental plane which will ultimately broaden the curiosity of the child, performing explorations of the physical world and allowing for new abstractions. The authors defend the teaching of chemistry for children, not with excessive work on contents with a high level of abstraction, but with themes compatible with the degree of psychological development of these children. Experimental approaches involving chemistry in the first grades of schooling are feasible and possible alternatives for expanding the forms of knowledge and of construction in the childhood.

Keywords: Chemistry; Experiments; Constructivism; Childhood.

\section{RESUMEN}

La elaboración de propuestas educativas para el trabajo con los niños debe realizarse en consonancia con el contexto histórico en el que viven estos niños. En ese sentido, las prácticas desarrolladas en décadas anteriores todavía permean el currículo de la educación infantil y primaria, lo que resulta en una incompatibilidad entre estos cuerpos y subjetividades. En medio de las actuales políticas de cambios curriculares, se hace necesaria una mirada más profunda a los temas relacionados con la escuela, el currículo y la planificación de la educación, teniendo en cuenta que el enfoque constructivista, aunque establecido en décadas anteriores, respalda teóricamente la elaboración de propuestas metodológicas para la educación. Así, se propone la realización de actividades envolviendo experimentos químicos, buscando representaciones en el plano mental que amplíen la curiosidad, permitan el descubrimiento del mundo físico y nuevas abstracciones. Defiendo que se enseñe química a los niños, no con un trabajo excesivo con contenido de alto nivel de abstracción, pero con temáticas compatibles con el grado de desarrollo psicológico de estos niños. Enfoques experimentales que envuelven a la química en los primeros años de escolarización, como alternativas viables y posibles para ampliar las formas de construcción del conocimiento en la infancia.

Palabras clave: Química; Experimentos; Constructivismo; Infancia.

\section{INTRODUÇÃO}

A importância de se considerar a infância em seu contexto histórico e social tem sido explicitada de forma crescente e permeia discursos políticos, econômicos e educacionais. Para alguns teóricos, a infância é uma típica descoberta da modernidade, e sua gênese está diretamente relacionada ao desenvolvimento da escolarização, entre outros fatores tais como: a influência do cristianismo e as novas formas de vida familiar (ARIÈS, 1981). Os estudos de Ariès (1981) reafirmam a concepção de infância "como algo que vai sendo montado, criado a partir de novas formas de falar e sentir dos adultos" (GHIRALDELLI JR, 2000, p. 49) em detrimento de uma noção da infância como uma etapa natural do desenvolvimento humano.

Ao considerar a infância como a fase da invenção, utiliza-se a construção social para compreender o sujeito infantil como aquele que se constitui a partir de práticas culturais, 
típicas de um contexto histórico particular. A concepção da criança como um adulto em miniatura perdurou até o século XVII, em que se considerava não haver diferenças destacadas entre raciocínio, sentimentos e ações de adultos e infantes. Para Corazza (2002), quando analisada a história da infância, observa-se uma ausência quase generalizada na antiguidade e também na Idade Média, visto que o dispositivo de infantilidade não operava para, especificamente, criar o 'infantil', embora já maquinasse como máquina, que vinha operativamente funcionando.

Além disso, as preocupações modernas acerca da infância traduziram o reconhecimento desta fase como desenvolvimento psicológico humano, no qual incorporaram o diálogo científico de diversos campos do saber com as práticas pedagógicas e sociais que se estabeleceram. Haja vista que as classes escolares passaram a ser compostas por crianças de mesma idade, enquanto os intelectuais defendiam a existência de diferenças entre o intelecto delas e dos adultos (CORAZZA, 2002).

$\mathrm{Na}$ história da ciência, recentemente, a infância - constituída segundo perspectivas culturais e, também, biológicas - passou a ser concebida como uma época especial do desenvolvimento, em que o sujeito necessita de cuidados, proteção e supervisão. Segundo Assis e Assis (2002, p. 18),

\footnotetext{
o ser humano traz consigo ao nascer as possibilidades orgânicas de construir um sistema de signos que lhe permite comunicar-se por meio da linguagem e de construir também todo o conhecimento que durante milênios a humanidade descobriu e inventou juntamente com um sistema de princípios e valores morais vigentes na sociedade a qual pertence. Ao contrário dos animais, o homem ao nascer não traz consigo mecanismos hereditários completamente montados que são ativados ao contato com a experiência, os comportamentos que possibilitam sua adaptação ao mundo são adquiridos a partir das trocas que o bebê começa a estabelecer com o meio físico e social desde o seu nascimento.
}

O nascimento das instituições dedicadas à educação infantil se deu na França em pleno século XVIII, para solucionar problemas relativos à pobreza, aos maus-tratos e ao abandono de crianças pequenas, filhas de trabalhadores fabris, fundidores e mineiros. Entretanto, o tratamento a ser dado para estas crianças dividia opiniões. Tendo em vista que os segmentos mais avantajados financeiramente defendiam a ideia de um tratamento ligado à ocupação de tempo e piedade (OLIVEIRA, 2003). Desse modo, grande parte das instituições infantis, nacionais e internacionais, organizaram seus serviços, baseando-se em atividades de assistência, custódia e higiene das crianças pequenas.

A década de 80 foi um período de grande importância para a educação infantil, uma vez que nela se ampliaram o debate em função da adaptação das funções destas instituições 
Dossiê: Diálogos Interdisciplinares em Psicologia da Educação

|A Química, o imaginário e as crianças: notas sobre o currículo pós-moderno|

|Aldo Sena de Oliveira | Patrícia Bulegon Brondani | Lidiane Meier |

que recebiam as crianças, a partir dos movimentos populares da década anterior (WAJSKOP, 1995). Em vista disso, cresceram as reflexões e as reivindicações por espaços de educação e cuidados coletivos para crianças com idades entre zero a seis anos de idade. É importante destacar que houve abertura política que viabilizou o reconhecimento social dos manifestos populares, culminando na legitimização do direito das crianças, por intermédio da Constituição de 1988 (Art. 208, e inciso IV) como dever do Estado e o atendimento à infância.

Nascidas para atender as crianças pobres, as instituições infantis que recebiam financiamento ou eram mantidas pelo poder público atuaram em muitas situações de forma compensatória a fim de minimizar as carências das crianças e de seus familiares. Nessas, as propostas educacionais foram permeadas por uma visão assistencialista, para além dos propósitos de uma educação pautada em questões curriculares, de desenvolvimento psicológico e com vistas às aprendizagens conceituais.

As atuais tendências educacionais acenam para a proposição de uma educação que forneça a integração de aspectos físicos, emocionais, afetivos, cognitivos e sociais da criança. Entretanto, coexistem problematizações acerca do cuidar/educar, do papel do afeto nas relações pedagógicas e sobre o educar para o conhecimento ou desenvolvimento. Estas indagações permeiam as proposições curriculares e fornecem meios para a elaboração de propostas pedagógicas para a educação infantil, com objetivo de:

propiciar situações de cuidados, brincadeiras e aprendizagens orientadas de forma integrada e que possam contribuir para o desenvolvimento das capacidades infantis de relação interpessoal, de ser e estar com os outros em uma atitude básica de aceitação, respeito e confiança, e o acesso, pelas crianças, aos conhecimentos mais amplos da realidade social e cultural (BRASIL, 2002, p. 23).

\section{O DISCURSO CONTEMPORÂNEO E A(S) INFÂNCIA(S)}

Considerando as perspectivas atuais, o termo infância adquire uma conotação polissêmica e denota o entendimento de que a noção e a realidade de infância variam de acordo com a classe social a que a família desta criança pertence, ao lugar em que ela vive seja área urbana, rural, periferia de grandes cidades, pequenas cidades do interior e/ou pelas diferenças culturais, religiosas, sociais, entre outros (DAL COLETO, 2014).

Nesse contexto e com o avanço em pesquisas nas áreas de Ciências Humanas especialmente na educação, a sociologia e a psicologia - intensificaram-se as preocupações 
Dossiê: Diálogos Interdisciplinares em Psicologia da Educação

|A Química, o imaginário e as crianças: notas sobre o currículo pós-moderno|

|Aldo Sena de Oliveira | Patrícia Bulegon Brondani | Lidiane Meier |

em como receber as crianças nas instituições escolares de modo a viabilizar o desenvolvimento de uma educação de qualidade. De acordo com Nascimento (2007),

considerando que cada criança é única, nosso desafio está em desenvolver uma escuta atenta e um olhar sensível às produções infantis, que vão nos informar sobre seus conhecimentos, interesses e as hipóteses que levantam para a solução de problemas. Essa escuta e olhar sensíveis revelam as aprendizagens que não estão somente nos livros, mas as aprendizagens que são fruto das interações com o meio, que passam pelo desejo e pela superação de desafios, que partem tanto do mundo exterior como da vontade íntima da criança de ultrapassar seus limites. Assim, para a elaboração desses documentos devemos ter em mente a realidade sociocultural e os desejos das crianças e de suas famílias (NASCIMENTO, 2007, p. 16).

Apesar dos inúmeros avanços dos últimos anos, as práticas educativas, desenvolvidas na educação infantil e nas primeiras séries do ensino fundamental, ainda se caracterizam de um modo geral por uma incompatibilidade entre as proposições pedagógicas, inspiradas no século passado e neste novo contexto histórico imerso em tecnologias digitais no qual as crianças estão imersas. Por um lado, o fato é que esta inadequação tornou-se mais evidente nos últimos anos, assim como foi a criação de um ajuste quase perfeito entre esses organismos e as subjetividades; por outro lado surgiram dispositivos de comunicação e informação móveis, como telefones celulares e computadores portáteis com acesso à internet (SIBILIA, 2012).

As crianças da pós-modernidade são incompatíveis com os dispositivos curriculares, que fundamentam as práticas pedagógicas, criados em décadas anteriores, como a base crítica que permeia as práticas na educação infantil e no ensino fundamental. Assim, as novas subjetividades florescem e manifestam sua flagrante incompatibilidade com tais ferramentas curriculares e se reúnem com outros artefatos (SIBILIA, 2012).

Para minimizar essas incompatibilidades entre as subjetivas e as propostas curriculares, novas proposições pedagógicas e políticas públicas para a infância têm sido elaboradas para a educação infantil e para as etapas iniciais do ensino fundamental, como forma de minimizar o caráter assistencialista que desconsideram a especificidade educativa das crianças em suas faixas etárias e que, historicamente, permeiam as práticas educativas para a infância (OLIVEIRA et al., 2016).

Nesse sentido, as Diretrizes Curriculares Nacionais da Educação Infantil (DCNEI - Resolução CNE/CEB no 05/09, artigo $4^{\circ}$ ) acenam para a compreensão da criança como um sujeito histórico e de direitos, que brinca, imagina, fantasia, deseja, aprende, observa, experimenta, narra, questiona e constrói sentidos sobre a natureza e sobre a sociedade, produzindo cultura. Essa visão denota e preconiza o direito das crianças ao acesso a 
processos de apropriação, de renovação e de articulação de saberes e conhecimentos, como requisito para a formação humana, para a participação social e para a cidadania, desde seu nascimento até seis anos de idade.

A construção de conhecimentos pela criança se dá pela interação com os seus pares, com os objetos do conhecimento e com os adultos, como forma de conhecer o mundo social, construir o conhecimento físico e desenvolver linguagens. As interações viabilizam o desenvolvimento de propriedades cognitivas que devam ser consideradas na elaboração de atividades nos espaços escolares e do currículo para a educação infantil e para o ensino fundamental (OLIVEIRA et al., 2016).

Assim, o currículo deverá ser resultado da articulação dos saberes e das experiências das crianças aos conjuntos de conhecimentos socializados pela humanidade, levando em consideração os aspectos culturais, artísticos, ambientais, científicos, tecnológicos (DCNEI, Art. $3^{\circ}$ ) éticos, políticos e estéticos (Resolução CNE/CEB 05/09, artigo 6 ${ }^{\circ}$ ). Nesse sentido, apenas uma ação integrada entre as comunidades (familiares, escolares) e o poder público (principalmente no que tange à elaboração de políticas) viabiliza e assegura o direito das crianças à proteção, à saúde, à liberdade, à confiança, ao respeito, à dignidade, à cultura, às artes, à brincadeira, à convivência e à interação com o outro.

Diante do exposto, é importante explicitar a necessidade de implementação de ações em consonância ao Plano Nacional de Educação (PNE), especialmente no que tange aos objetivos de fomentar a qualidade da educação básica em todas as etapas e modalidades, com melhoria do fluxo escolar e da aprendizagem.

\section{PSICOLOGIA, CONSTRUTIVISMO E APRENDIZAGEM INFANTIL}

Para melhor compreensão de como ocorre a aprendizagem infantil, além de analisar as questões epistemológicas que envolvem uma série de elementos de ordem pedagógica, é interessante avaliar o processo segundo padrões de base neurofisiológica, especialmente à comunicação neuronal. Em condições especiais, como alterações no desenvolvimento e nas lesões neurológicas, em que determinadas áreas do cérebro encontram-se alteradas, trabalhos de intervenção cognitiva, comportamental, educacional e funcional são essenciais para formar e fortalecer novas redes de sinapses, promovendo, consequentemente, melhor capacidade de aprendizagem e autonomia.

A atividade cerebral e os processos cognitivos são de apropriação da neuropsicologia, que faz uso de modelos de cognição pautados a partir da Psicologia 
Cognitiva. Analisando as atuais perspectivas no campo da psicologia, a aproximação entre a cognição e a atividade cerebral também podem ser feitas a partir do referencial piagetiano. Como sugere Becker (2005), estão na hora de correlacionar os achados de Piaget e os achados da neurologia.

Segundo Ciasca (2008), a aprendizagem está caracterizada pela integridade básica de três níveis:

- Funções psicodinâmicas: implicam a assimilação hierárquica pelo organismo das informações que vem do meio externo. Para tanto, é necessário integridade psicoemocional para que a aprendizagem ocorra.

- Funções do sistema nervoso periférico: promovem a aprendizagem por meio de vias sensoriais, assim sendo, pouca estimulação sensorial prejudica o cérebro quanto ao desenvolvimento básico e necessário para o amadurecimento dos processos psicológicos;

- Funções do sistema nervoso central: armazena, elabora e processa informações quando o organismo responde de maneira apropriada.

Conforme afirmação anterior, a educação construtivista pode ser compreendida sob a égide dos estudos desenvolvidos por Piaget (1990), o qual reconhece a importância na compreensão de como as crianças "constroem" ativamente o conhecimento sobre o mundo físico, por intermédio de suas experiências.

Essa construção de conhecimentos acerca do mundo físico e do conhecimento lógico-matemático são feitas utilizando-se testes de hipóteses, refinamento de ideias e compreensão de como a natureza se organiza. A escolha pela realização e pela observação de atividades permite a exploração do mundo físico e denotam as indagações acerca da aprendizagem infantil, a fim de traduzir o anseio de utilização de novas práticas pedagógicas para o trabalho com as crianças. Nesse trabalho, algumas indagações tem permeado a pesquisa com as crianças: Quais conhecimentos socializar? Quais os interesses das crianças entre 4 e 12 anos de idade? O que elas são capazes de aprender? Como organizar as atividades de forma a garantir o máximo de possibilidades de aprendizado?

$\mathrm{Na}$ educação infantil e no ensino fundamental, as crianças devem encontrar em suas salas de aula, situações que lhes permitam explorar elementos que constituem a realidade que as cercam. O fazer pedagógico deve contemplar ações que estimulem a curiosidade e o interesse por interpretar os fenômenos que ocorrem no universo em que estão inseridas as crianças. Experimentar, imaginar, descobrir e criar deve ser forças motrizes da construção do conhecimento, na medida em que a educação deve favorecer situações propiciais para que estas ações se consolidem e levem a aprendizagens 
significativas (OLIVEIRA et al., 2016).

A escolha pela investigação das propriedades atribuídas aos fenômenos físicos como base para o estudo que se empreende na educação infantil também tem origem na observação da prática pedagógica. Embora esse domínio do saber apareça nos Referenciais Curriculares Nacionais (BRASIL, 2002) muito pouco se tem feito na prática. A manipulação de objetos e materiais de forma programada pelo(a) docente, pode favorecer situações que contribuam para a construção dos conhecimentos físico e lógico-matemático.

Gonçalves (1991) e Carvalho (1998) já apresentaram há duas décadas a importância do Ensino de Ciências no Ensino Fundamental, inspiradas pela epistemologia genética de Piaget (1975) e os trabalhos de Kamii e Devries (1988). Esses autores propõem atividades que permitem aos estudantes dos anos iniciais do Ensino Fundamental construir explicações causais sobre os fenômenos físicos a partir de suas próprias ações sobre um objeto de investigação.

Para Piaget (1975), a criança estabelece relações entre seu mundo e seu imaginário mediante contato ativo entre pessoas e objetos. Essa relação permite que a criança desenvolva seu raciocino abstrato, pela passagem de estágios de desenvolvimento cognitivo, os quais apresentam padrões maturacionais e podem ter relações com o desenvolvimento biológico. A cognição atua na manutenção do desenvolvimento psicológico e elabora-se por meio de trocas constantes com o meio, em que a inteligência se desenvolve. Para o autor, os objetivos do desenvolvimento envolvem a habilidade de se chegar ao raciocínio abstrato, de modo a pensar em situações hipotéticas de forma lógica e estruturar operações lógicas em estruturas superiores e com complexidade crescente. Para Piaget (1990):

pode dizer-se que toda necessidade tende primeiro a incorporar as pessoas e as coisas na atividade própria do sujeito, portanto a "assimilar" o mundo exterior às estruturas já construídas, e, segundo, a reajustar estas em função das transformações sofridas, portanto em "acomodá-las" aos objetos externos (PIAGET, 1990, p. 17.)

Enquanto o conhecimento físico resulta da abstração empírica, envolvendo as propriedades dos objetos como as características materiais, a experiência lógico-matemática envolve as operações mentais da criança sobre o mundo e, também, das ações sobre os objetos, não podendo ser ensinada por simples repetição ou verbalização. A implementação de temáticas envolvendo o construtivismo, permeadas pelo conhecimento físico é dada pelas modificações no currículo escolar (DAL COLETO, 2014). 
Dossiê: Diálogos Interdisciplinares em Psicologia da Educação

|A Química, o imaginário e as crianças: notas sobre o currículo pós-moderno|

|Aldo Sena de Oliveira | Patrícia Bulegon Brondani | Lidiane Meier |

\section{O CURRÍCULO DAS CIÊNCIAS E A QUÍMICA PARA CRIANÇAS}

Para uma análise preliminar acerca do currículo, é de extrema importância a compreensão das Diretrizes Curriculares Nacionais para a Educação Infantil-Resolução CNE/CBE n. 5, de dezembro de 2009. Essas diretrizes devem ser contempladas na elaboração das propostas pedagógicas de cada estabelecimento, preconizado no

\footnotetext{
Art. $3^{\circ} \mathrm{O}$ currículo da Educação Infantil é concebido como um conjunto de práticas que buscam articular as experiências e os saberes das crianças com os conhecimentos que fazem parte do patrimônio cultural, artístico, ambiental, científico e tecnológico, de modo a promover o desenvolvimento integral de crianças de 0 a 5 anos de idade (BRASIL, 2009, p. 01).
}

Além da definição do currículo, há necessidade de se reconhecer a criança como sujeito de direitos e que deve estar no centro do processo educativo e do planejamento curricular, tendo em vista que

\footnotetext{
as propostas pedagógicas da Educação Infantil deverão considerar que a criança, centro do planejamento curricular, é sujeito histórico e de direitos que, nas interações, relações e práticas cotidianas que vivencia, constrói sua identidade pessoal e coletiva, brinca, imagina, fantasia, deseja, aprende, observa, experimenta, narra, questiona e constrói sentidos sobre a natureza e a sociedade, produzindo cultura (BRASIL, 2009, p. 01).
}

De acordo com propostas pautadas no construtivismo, o Ensino de Ciências deve favorecer o aprimoramento do raciocínio em detrimento da simples memorização, viabilizando o desenvolvimento de criticidade em vez de simples repetições. Deverão ser pensadas situações nas quais as crianças se encontrem desalojadas mentalmente e procurem uma solução para os desafios que a elas são apresentados. Além disso, deverão ser criadas situações nas quais são desafiadas e convidadas a estabelecer e comprovar suas hipóteses, a partir de discussão ampla com seus pares e com o(a) professor(a) (DAL COLETO, 2014).

A investigação da relevância de atividades experimentais na aprendizagem das ciências tem sido explicitada nos últimos anos. Entretanto, as pesquisas e as produções bibliográficas enfatizam a ludicidade destes ambientes experimentais, e pouco tem sido discutido acerca dos progressos/avanços no desenvolvimento das estruturas lógicas, decorrentes da utilização dessas, especialmente na educação infantil e nas primeiras séries do ensino fundamental. No caso da Química, as produções enfatizam a elaboração de experimentos, cujas abordagens se restringem às metodologias de adaptação de experimentos clássicos para que possam ser manuseados pelas crianças (OLIVEIRA et al., 
2016).

Levando-se em consideração as novas perspectivas curriculares para o Ensino Médio, sancionadas pelo presidente Michel Temer em 16 de fevereiro, reforça-se a necessidade do desenvolvimento destas atividades na educação infantil e também no ensino fundamental, uma vez que o conteúdo experimental da Química tradicionalmente é apresentado no ensino médio. Se o(a) estudante não fizer a opção pelo campo das Ciências Naturais, fatalmente poderá ter prejuízos na sua formação, se as atividades experimentais não forem inseridas em momentos anteriores, comprometendo a visão global de ciência e dificultando às ações de divulgação científica.

É fato que a importância da experimentação no ensino de Química tem sido objeto de diversas teorizações nas últimas décadas, podendo ser a experimentação uma estratégia eficiente para demonstrar os conteúdos trabalhados e para se resolver os problemas reais que permitem um ensino contextualizado. A investigação estimula o aluno a levantar hipóteses, questionamentos e discutir os fenômenos apresentados durante a aula (SILVA; ZANON, 2000). Neste processo de construção de conhecimentos, os experimentos devem propiciar aos estudantes a possibilidade de realizar, registrar, discutir com os colegas, refletir, levantar e avaliar as hipóteses e as explicações, a fim de discutir com o professor todas as etapas do experimento (FRANCISCO JUNIOR et al, 2008).

Nesse sentido, atividades experimentais envolvem a química, sendo de grande relevância no sentido de viabilizar possibilidades na apresentação de ideias e na exposição de diferentes argumentos para explicar as observações a partir do experimento. Oliveira e colaboradores (2016) desenvolveram uma série de experimentos com crianças, correlacionando experimentos de Química com as provas operatórias de Piaget (1990). O intuito era analisar as representações mentais e as compreensões infantis acerca de situações que envolvessem os experimentos, para compreender como estas crianças entendiam as mudanças de estado físico, as alterações de cor, o aquecimento e o resfriamento... Além de compreender tais abordagens conceituais, os autores verificaram uma relação entre a compreensão e as manifestações do pensamento de acordo com as proposições da epistemologia genética.

Quando as crianças foram questionadas acerca dos conceitos, percebeu-se que as falas das crianças afirmaram o caráter egocêntrico nas manifestações do ideário infantil e denotaram, no caso das ciências, os conflitos cognitivos que engendram uma tentativa de mudança conceitual. Enquanto refletem, as crianças intencionalmente ou não, provocam sensíveis alterações no plano cognitivo e, assim, quando desafiadas a pensar nos estados 
|Aldo Sena de Oliveira | Patrícia Bulegon Brondani | Lidiane Meier |

físicos e nas alterações colorimétricas, típicas de experimentos químicos, surge a possibilidade de apropriação de novos domínios cognitivos. Estes domínios são reflexos de novas apropriações e traduzem implicações pedagógicas importantes (OLIVEIRA et al., 2016).

Ademais, o desenvolvimento cognitivo ocorre segundo amadurecimento das estruturas lógicas e do sistema nervoso, mas a idade biológica não deve ser utilizada isoladamente para fins de classificação de um certo estágio de desenvolvimento intelectual. Os experimentos químicos realizados com as crianças podem ser importantes por viabilizar (por meio da fala, do desenho e das representações gráficas) a ação docente no sentido de potencializar as aprendizagens, que são múltiplas.

Estas apropriações incentivam novas pesquisas na área de Química para crianças e são de extrema importância no desenvolvimento de práticas curriculares, que estejam em consonância com a atual dimensão de infância, que permitam intervenções nos espaços escolares e no desenvolvimento de ações pedagógicas para crianças em suas primeiras etapas da escolarização (OLIVEIRA et al., 2016).

\section{CONSIDERAÇÕES FINAIS}

Do ponto de vista teórico, a realização de atividades experimentais, envolvendo a química e as crianças, pode favorecer a autonomia e o desenvolvimento dessas, a fim de ampliar as possibilidades cognitivas nessa fase da infância. Essas atividades favorecem a explicação dos fenômenos que ocorrem ao seu redor; viabilizam a formação de novas hipóteses e no aprimoramento do raciocínio lógico e contribuem para que a criança entenda a relação entre a ciência e a sociedade.

Ainda que seja possível observar um notório avanço no reconhecimento das atividades experimentais, faz-se necessário um olhar dotado de maior criticidade, no sentido de repensar as atividades com as crianças para além dos aspectos lúdicos. Viabilizar uma alternativa pedagógica mais consistente e condizente com as possibilidades intelectuais e experimentais por parte delas implica a necessidade de se conhecer mais profundamente como se dá a aprendizagem, inclusive levando em consideração os seus aspectos neurofisiológicos.

Defende-se a elaboração de propostas pedagógicas e curriculares que possibilitem uma aproximação entre as crianças e as ciências, com vistas ao aprendizado e ao progresso intelectual especialmente na educação infantil e nas primeiras etapas do ensino 
fundamental.

\section{REFERÊNCIAS}

ARIÈS, Philippe. História social da criança e da família. Trad. Dora Flaksman. 2. ed. Rio de Janeiro: Zahar Editores, 1981.

ASSIS, Orly Zucatto Mantovani de; ASSIS, Múcio Camargo. PROEPRE: fundamentos teóricos e práticas pedagógicas para educação infantil na formação de professores. Campinas: Unicamp/LPG/FE, 2002.

BECKER, Fernando. Um divisor de águas. Viver, Mente e Cérebro. (Coleção Memória da Pedagogia, n. 1) Rio de Janeiro: Ediouro; São Paulo: Segmento-Duetto, 2005. p. 24 a 33.

Ministério da Educação. Referencial curricular nacional para a educação infantil. Brasília, DF: MEC/SEF/DPE/COEDI, 2002.

Ministério da Educação. Resolução CNE/CEB, n. 5, de 17 de dezembro de 2009. Diretrizes Curriculares Nacionais para a Educação Infantil. Diário Oficial [da] República Federativa do Brasil, Brasília, DF, 2009.

CARVALHO, Ana Maria Pessoa de; VANNUCCHI, Andrea Infantosi; BARROS, Marcelo Alves. Ciências no Ensino Fundamental: o conhecimento físico. São Paulo: Scipione, 1998.

CIASCA, Sylvia Maria. Distúrbios de Aprendizagem: proposta de avaliação interdisciplinar. 3. ed. São Paulo: Casa do Psicólogo, 2008.

CORAZZA, Sandra Mara. Infância \& educação: era uma vez... quer que eu te conte outra vez? Petrópolis: Vozes, 2002.

DAL COLETO, Andréa Patapoff. Percursos para a construção de indicadores da qualidade da educação infantil. 2014. 466 f. Tese (Doutorado em Educação) Faculdade de Educação, Universidade Estadual de Campinas, Campinas, 2014.

FRANCISCO JÚNIOR, Wilmo Ernesto; FERREIRA, Luiz Henrique; HARTWIG, Dácio Rodney. Experimentação Problematizadora: Fundamentos Teóricos e Práticos para a Aplicação em Salas de Aula de Ciências. Química Nova na Escola, n. 30, p. 34-41, 2008.

GHIRALDELLI JR, Paulo. As concepções de infância e as teorias educacionais modernas e contemporâneas. Educação e Realidade, Porto Alegre, v. 25, n. 1, p. 45-58, 2000.

GONÇALVES, Maria Elisa Rezende. O conhecimento físico nas primeiras séries do primeiro grau. 1991. 221 f. Dissertação (Mestrado em Ensino de Ciências) - Instituto de Física e Faculdade de Educação, Universidade de São Paulo, São Paulo, 1991.

KAMII, Constance; DEVRIES, Rheta. O conhecimento físico na educação préescolar: implicações da teoria de Piaget. Porto Alegre: Artes Médicas, 1988. 
NASCIMENTO, Anelise Monteiro. Currículo e práticas pedagógicas na educação infantil. Revista Criança do Professor de Educação Infantil, Brasília, n. 43, p. 14-17, ago. 2007.

OLIVEIRA, Aldo Sena de; MACHADO, Anderson Luiz; SILVA, Ana Carolina Araújo da. The importance of Piagetian reference for the elucidation of conceptual development in Chemistry. Creative Education, Província de Hubei, CN, v. 7, n. 3, p. 491-499, mar. 2016.

OLIVEIRA, Zilma de M. Ramos. Diretrizes para a formação de professores de educação infantil. Revista Pátio Educação Infantil, Porto Alegre, v. 2, p. 6-9, ago./nov. 2003.

PIAGET, Jean. A equilibração das estruturas cognitivas. Rio de Janeiro: Zahar Editores, 1975.

Epistemologia genética. São Paulo: Martins Fontes, 1990.

SIBILIA, Paula. Redes ou Paredes: escola em tempos de dispersão. Rio de Janeiro: Contraponto, 2012.

SILVA, Lenice de Arruda; ZANON, Lenir Basso. A experimentação no ensino de Ciências. In: SCHNETZLER, Roseli Pacheco; ARAGÃO, Rosália Maria Ribeiro de. (Org.). Ensino de ciências: fundamentos e abordagens. São Paulo: CAPES/UNIMEP, 2000. p. 120- 153.

WAJSKOP, Gisela. O brincar na educação infantil. Caderno de Pesquisa, São Paulo, n. 92, p. 62-69, fev. 1995. 